\title{
OBESITY EFFECT ON THE COURSE OF ABDOMINAL TRAUMA
}

DOI: 10.36740/WLek202108109

\author{
Madona 0. Gogiya', Igor V. Belozorov', Vira V. Zlatkina ${ }^{2}$, Iuliia M. Mozgova ${ }^{2}$, Maksym E. Vodka', \\ Oleksandr E. Feskov ${ }^{3}$, Mykhailo S. Myroshnychenko \\ ${ }^{1}$ V. N. KARAZIN KHARKIV NATIONAL UNIVERSITY, KHARKIV, UKRAINE \\ ${ }^{2}$ KHARKIV NATIONAL MEDICAL UNIVERSITY, KHARKIV, UKRAINE \\ ${ }^{3}$ KHARKIV MEDICAL ACADEMY OF POSTGRADUATE EDUCATION, KHARKIV, UKRAINE
}

\begin{abstract}
The aim was to determine the role of obesity in the development of fatal complications and deaths in victims with abdominal trauma.

Materials and methods: The study was conducted on the basis of the Department of Polytrauma at the Municipal Health Care Institution of Kharkiv City Council"0.I. Meshchaninov City Clinical Hospital of Ambulance and Emergency Care". The authors have analyzed the case histories of 240 patients with abdominal trauma depending on the presence of obesity, which was determined by BMI (body mass index) and/or waist circumference (WC).

Results: Complications were found in 93 (38.8\%) victims, 34 (14.2\%) victims died. It was found that the overall incidence of complications, respiratory and hemocoagulation complications, the incidence of multiple organ failure (MOF) and mortality significantly increased in obese victims. Determination of obesity by the value of the BMI during hospitalization was possible in $41.7 \%$ of victims. The identification of WC turned out to be no less informative, but more accessible.

Conclusions: Obesity increases the incidence of complications and mortality in victims of abdominal trauma, and is a marker of a negative prognosis. Traditional assessment of BMI during hospitalization in most victims with abdominal trauma is not possible due to the severity of the condition and/or the presence of combined injuries. A good alternative to determining obesity in victims with abdominal trauma is a WC (more than $88 \mathrm{~cm}$ in women and more than $102 \mathrm{~cm}$ in men).
\end{abstract}

KEY WORDS: obesity, complications and deaths, abdominal trauma

Wiad Lek. 2021;74(8):1829-1833

\section{INTRODUCTION}

Damage of abdominal cavity and extraperitoneal space is one of the common causes of severe complications and death of mechanical trauma victims. Abdominal injuries are found in $86.4 \%$ of deaths due to trauma [1].

The severities of primary and vividly expressed functional disorders that occur in response to trauma are often mentioned among the most significant factors, complicating the course of abdominal trauma.

These indicators are used in determining the treatment tactics and prediction of the injury consequences by quantifying structural damage in the form of anatomical scales of its severity (AIS (Abbreviated injury scale), ISS (Injury severity score), NISS (New injury severity score), APS (Anatomic Profile Score), PTS (Polytraumaschlussel, etc.) or the severity of functional disorders (Glasgow coma scale (GCS), TS (Trauma Score), RTS (Revised Trauma Score, etc.)) [2].

However, these scales do not take into account individual characteristics of the victim, which affect both the initial response to the trauma and subsequent compensatory and restorative processes. The risk factors for adverse course of traumas often include concomitant pathology [3, 4]. Overweight and obesity, prevalence of which is increasing worldwide, is noteworthy among the concomitant pathology [5].
The results of studies on the effects of overweight and obesity on the course of trauma are ambiguous. A.K. Chen et al. found an increase in the frequency of interventions and mortality in patients with liver injury with increased BMI [6], while C.Y. Fu et al., in contrast, found that obesity reduced the incidence of blunt abdominal trauma and operations due to damage of the abdominal organs [7]. This indicates the need for further research in this direction.

\section{THE AIM}

The aim was to determine the role of obesity in the development of fatal complications and deaths in victims with abdominal trauma.

\section{MATERIALS AND METHODS}

The study was conducted on the basis of the Department of Polytrauma at the Municipal Health Care Institution of Kharkiv City Council "O.I. Meshchaninov City Clinical Hospital of Ambulance and Emergency Care". The authors have analyzed the case histories of 240 patients with abdominal trauma hospitalized during 2017-2020. The average age of patients was $(37.1 \pm 13.2)$ years (from 18 to 88 years), among them there were 189 men $(78.8 \%)$. 
We studied the nature of trauma, frequency and structure of complications and deaths depending on nutrition. $\mathrm{Nu}-$ tritional status was studied by anthropometric indicators - weight $(\mathrm{kg})$, height $(\mathrm{cm})$ and WC $(\mathrm{cm})$. Based on the obtained data, the BMI was calculated according to the formula: $\mathrm{BMI}=$ weight $(\mathrm{kg}) /$ height $\left(\mathrm{m}^{2}\right)$.

The victims were weighted on the floor scales for medical purposes, height was measured using a height meter in a standing position, using a centimeter tape for medical purposes in a supine position (in an unstable condition or in the case of the spine, pelvis or lower extremities injury). In severe cases of consciousness disturbance, skeletal trauma with damage to the spine, pelvis and/or lower extremities, as well as unstable hemodynamics due to blood loss and/or traumatic shock, weight was measured in the postoperative period in the intensive care unit after stabilization and, if possible, verticalization of the patient.

WC was measured in the middle between the lower border of the thorax and the iliac crest or at the level of the upper border of the iliac crest in a standing or lying position using a centimeter tape for medical purposes [8].

Anthropometric indicators were assessed according to the WHO recommendations: normal weight - BMI up to $18-25 \mathrm{~kg} / \mathrm{m}^{2}$; increased weight - BMI $25-29.9 \mathrm{~kg} / \mathrm{m}^{2}$; obesity - from $30 \mathrm{~kg} / \mathrm{m}^{2}$ and more. Signs of abdominal obesity were also considered WC more than $88 \mathrm{~cm}$ in women and more than $102 \mathrm{~cm}$ in men [8].

We used AIS scale to assess the trauma severity of individual anatomical and functional areas (AFA), and the total severity of the combined trauma - according to ISS scale.

A package of statistical programs PSSP was used to process the obtained results, applying methods of mathematical statistics. Qualitative indicators are described in the form of absolute quantity (n) and percentage (\%). Quantitative indicators were checked for distribution normality by means of Kolmogorov-Smirnov test: in normal distribution arithmetic mean and standard deviation $(\mathrm{M} \pm \mathrm{SD})$ and Student's criterion for comparison of data between groups were used for the description, in abnormal distribution - median of $25^{\text {th }}$ and $75^{\text {th }}$ quarters $\left(\mathrm{Me}\left[\mathrm{Q}_{25} ; \mathrm{Q}_{75}\right]\right)$ and the Mann-Whitney $\mathrm{U}$ test for data comparison. Qualitative indicators were compared using Fisher's exact test or $\chi 2$ test. The difference between the groups was considered significant when the probability of the null hypothesis was less than $5 \%(\mathrm{p}<0.05)$. The correlation analysis was performed by the Spearman method. In addition, we calculated the relative risk (RR) of lethal outcome, using an online calculator (https://medstatistic. $\mathrm{ru} /$ calculators/calcrisk.html) in the form of RR and $95 \%$ confidence interval $(95 \% \mathrm{CI})$.

\section{RESULTS}

The range of injuries in the victims included in the study was very wide. Isolated abdominal trauma was diagnosed only in $62(25.9 \%)$ people, a combined abdominal trauma was diagnosed in $178(74.2 \%)$ victims. $133(55.4 \%)$ victims had isolated injuries of the abdominal cavity or extra-peritoneal space, in all other cases, injuries of two or more organs were detected. Spleen trauma was found in 102 (42.5\%) victims, liver trauma in $81(33.8 \%)$, small intestine injury in 47 (19.6\%) and colon injury in 14 (5.9\%). 32 (13.3\%) victims were diagnosed with omental injuries and $37(15.4 \%)$ with mesenteric injuries, gallbladder injury - in $8(3.3 \%)$ cases, gastric injury was diagnosed in $4(1.7 \%)$ victims. In 230 (95.8\%) victims internal organ injuries were complicated by hemoperitoneum, signs of peritonitis were found in 31 (12.9\%) victims. Among the traumas of the extraperitoneal space, kidney damage was most often found - 46 (19.2\%) and pancreas - $27(11.2 \%)$ cases, less often - bladder injury - $13(5.4 \%)$ cases. Extraperitoneal hematoma was found in $63(26.7 \%)$ victims.

Among the combined injuries, thoracic trauma was the most common - 129 (53.8\%) victims; skeletal trauma was detected in 96 (40\%) victims; $84(35 \%)$ patients had a traumatic brain injury (TBI). The severity of injury to the ISS throughout the sample was $22[16 ; 27]$ points (from 4 to 48 points): mild injury - $13(5.4 \%)$ cases, moderate $120(50.0 \%)$ cases, severe - $90(37.5 \%)$ and extremely severe $-17(7.1 \%)$ cases.

$93(38.7 \%)$ victims had clinically significant complications in the post-traumatic period. Respiratory - 41 (44.0\%), cardiovascular - 33 (35.5\%), wound - 29 (31.2\%), renal - $12(12.9 \%)$, delirium - $15(16.1 \%)$, cerebral edema $8(8.6 \%), 9(9.7 \%)$ - MOF dominated in the structure of complications. In isolated cases, we diagnosed intestinal obstruction, acute pancreatitis, intra-abdominal bleeding, peritonitis, pulmonary embolism (PE) or perforated duodenal ulcer in the postoperative period.

34 (14.2\%) victims died during hospital treatment. During the first 7 days, 12 (35\%) victims died, including 5 cases during the first day. The main cause of death was decompensated traumatic shock, in 2 cases it was edema and brain dislocation. 19 (29.4\%) patients died during the first 8-14 days, 8 (23.5\%) - during 15-28 days, 4 (11.8\%) victims died after the $28^{\text {th }}$ day. The main causes of death during this period were MOF, cardiac or cardiopulmonary insufficiency, cerebral edema, respiratory complications, PE and/ or intra-abdominal, wound and urological complications.

When studying the nutritional status of victims with abdominal trauma, it was found that the BMI was 26.6 $[24.4 ; 28.4] \mathrm{kg} / \mathrm{m}^{2}$, there were $75(31.3 \%)$ patients with normal weight (BMI up to $\left.25 \mathrm{~kg} / \mathrm{m}^{2}\right), 129(53.8 \%)$ - with increased weight (BMI $\left.25.0-29.9 \mathrm{~kg} / \mathrm{m}^{2}\right), 36(15.0 \%)$ - with obesity (BMI of 30.0 and more $\mathrm{kg} / \mathrm{m}^{2}$ ). The value of WC in women was $79.0[68.0 ; 89.0] \mathrm{cm}$, in men -89.0 [86.0; $97.5 \mathrm{~cm}$. Signs of obesity with an increase WC more than the threshold value (more than $88.0 \mathrm{~cm}$ in women and $102.0 \mathrm{~cm}$ in men) were found in $29(12.1 \%)$ victims. In general, signs of obesity - an increase BMI and/or an increase WC more than the threshold values were found in $50(20.8 \%)$ patients. It should be noted that there was a strong positive significant correlation between BMI and WC $\left(r_{s}=0.695 ; p<0.001\right)$, more significant in women than in men $\left(r_{s}=0.927, p<0.001\right.$, and $r_{s}=0.711, p<0.001$, respectively). 
Table I. The frequency of complications and mortality depending on the presence of obesity $-\mathrm{n}(\%)$.

\begin{tabular}{|c|c|c|c|}
\hline Complications or mortality & Obesity $(n=50)$ & No obesity $(n=190)$ & $\mathbf{p}^{1}$ \\
\hline Any complications & $38(76 \%)$ & $55(28.9 \%)$ & $<0.001$ \\
\hline Wound complications & $9(18 \%)$ & $20(10.5 \%)$ & $>0.05$ \\
\hline Respiratory complications & $25(50 \%)$ & $16(39.0 \%)$ & $<0.001$ \\
\hline Central nervous system complications & $3(6 \%)$ & $21(11.1 \%)$ & $>0.05$ \\
\hline Renal complications & $5(10 \%)$ & $7(3.7 \%)$ & $>0.05$ \\
\hline Cardiovascular complications & $9(18 \%)$ & $24(12.6 \%)$ & $>0.05$ \\
\hline Hemocoagulation complications & $3(6 \%)$ & $2(1.1 \%)$ & $<0.05$ \\
\hline MOF & $6(12 \%)$ & $3(1.6 \%)$ & $=0.001$ \\
\hline Mortality & $12(24 \%)$ & $22(11.6 \%)$ & $<0.05$ \\
\hline
\end{tabular}

Note. ${ }^{1}$ - the significance of the difference by the $x 2$ criterion.

Table II. The frequency of complications and mortality depending on the presence of obesity according to the results of WC measuring $-\mathrm{n}(\%)$.

\begin{tabular}{|c|c|c|c|}
\hline Complications or mortality & Obesity $(n=29)$ & No obesity $(n=211)$ & $\mathbf{p}^{1}$ \\
\hline Any complications & $19(66 \%)$ & $74(35.1 \%)$ & $<0.01$ \\
\hline Wound complications & $2(7 \%)$ & $27(12.8 \%)$ & $>0.05$ \\
\hline Respiratory complications & $9(31 \%)$ & $32(15.2 \%)$ & $<0.05$ \\
\hline Central nervous system complications & $1(3.4 \%)$ & $23(10.9 \%)$ & $>0.05$ \\
\hline Renal complications & $3(10 \%)$ & $9(4.3 \%)$ & $>0.05$ \\
\hline Cardiovascular complications & $7(24 \%)$ & $26(12.3 \%)$ & $>0.05$ \\
\hline Hemocoagulation complications & $3(10 \%)$ & $2(0.9 \%)$ & $=0.001$ \\
\hline MOF & $4(14 \%)$ & $5(2.4 \%)$ & $<0.01$ \\
\hline Mortality & $10(35 \%)$ & $24(11.4 \%)$ & $=0.001$ \\
\hline
\end{tabular}

Note. ${ }^{1}$ - the significance of the difference by the $x 2$ criterion.

Table III. The RR of fatal abdominal injury for individual indicators.

\begin{tabular}{ccc}
\hline Risk factor & RR & $\mathbf{9 5 \%} \mathbf{C l}$ \\
\hline ISS from 30 points and more & 5.011 & $2.781-9.029$ \\
\hline Severe thoracic trauma & 4.884 & $2.778-8.584$ \\
\hline Severe TBI & 3.032 & $1.619-5.677$ \\
\hline Severe skeletal trauma & 2.656 & $1.448-4.870$ \\
\hline Age of the victim from 60 years and more & 2.147 & $1.118-4.127$ \\
\hline Obesity (according BMI and/or WC) & 2.073 & $1.103-3.894$ \\
\hline Obesity (according to WC) & 3.032 & $1.619-5.677$ \\
\hline
\end{tabular}

We analysed the frequency of the complications and mortality and found that the overall frequency of complications increased significantly in obese victims (with increasing BMI and/or WC more than the threshold values) $\left(\mathrm{p}<0,001\right.$ criterion $\left.\chi^{2}\right)$, respiratory and hemocoagulation complications $\left(\mathrm{p}<0.001\right.$ and $\mathrm{p}<0.05$ by the criterion $\left.\chi^{2}\right)$. The frequency of MOF development $(\mathrm{p}=0.001)$ and mortality $(\mathrm{p}<0.05)$ has also increased significantly (table I).

The obtained data indicate that obesity is an aggravating factor in the course of trauma which must be taken into account when predicting its consequences. In most publications on this issue, nutrition is assessed on the basis of BMI. However, in real conditions during hospitalization and in the early postoperative period, weighing with standard equipment is impossible due to the serious condition of the victim. In our study, this was possible only in 100 $(41.7 \%)$ victims.

Measurement of WC was more accessible in the conditions of polytrauma department. With an increase in WC of more than threshold values, there was also a significant increase in the overall frequency of complications $(\mathrm{p}<0.01$ by criterion $\left.\chi^{2}\right)$, respiratory $(\mathrm{p}<0.05)$, hemocoagulation $(\mathrm{p}=0.001)$ complications and $\operatorname{MOF}(\mathrm{p}=0.001)$. The mortality $(p=0.001)$ was much higher (table II).

This makes it possible and feasible to use WC measurement to assess nutritional status. An excess in this indicator to higher threshold values is a reliable risk factor for complications and deaths in patients with abdominal trauma, especially when it is technically impossible to calculate BMI. 
The authors have additionally calculated RR of death for individual indicators (table III).

The obtained data show that the highest RR of death after the abdominal trauma depended on the severity of trauma on the ISS of 30 points or more, as well as a severe thoracic trauma or TBI. Severe skeletal trauma and the age of the victim $60+$ had a smaller impact. We found it very interesting that the RR of death from WC measurement was higher than when assessed for BMI and WC. We explain this by the greater value of the abdominal type of obesity than the increase in BMI over $30.0 \mathrm{~kg} / \mathrm{m}^{2}$.

\section{DISCUSSION}

Overweight and obesity are a serious health problem worldwide, the relevance of which has increased in recent decades [9]. Traditionally, weight is assessed on the basis of the BMI. Overweight (BMI over $25 \mathrm{~kg} / \mathrm{m}^{2}$ ) and, to a greater extent, obesity (BMI over $30 \mathrm{~kg} / \mathrm{m}^{2}$ ) is not only an independent pathological background but also a manifestation or risk factor of many chronic diseases, as well as a factor complicating the course of acute diseases and traumas. BMI and other anthropometric indicators have been shown to be strong predictors of mortality risk in general population [10]. Increased BMI is associated with increased mortality and complication rates in critically ill patients [11].

Other authors have found an increase in the frequency of complications and mortality in obese victims. In particular, according to the analysis results of treatment of almost 33 thousand victims with blunt trauma, it was found that pathological obesity increased the risk of complications $(\mathrm{OR}-1,8)$, the length of hospitalization (OR $1,2)$, duration of treatment in hospital $(\mathrm{OR}-1,15)$, and mortality -3.0 vs. $2.2(\mathrm{OR}-1.4)$ [12]. The risk of wound complications in obese women increased 2.5-4 times, while the risk of bedsores - 4-8 times [13]. In patients with penetrating abdominal trauma, the risk of infectious wound complications grew with increasing BMI, age, depending on the location of the injury (significantly increases with injuries of the hollow organs), with the need for blood transfusion [14]. The authors have found that obese patients who underwent laparotomy for abdominal trauma had a significantly higher mortality rate than normal weight patients (3.7\% vs. $2.4 \%)$. No differences were found in non-operated victims. According to the authors, this indicates the need for alternative treatment tactics in obese victims [15].

Thus, the results of our study indicate that obesity is a marker of a negative prognosis of abdominal trauma, which coincides with the results of other authors. In the available literature, the definition of these conditions is based on the calculation of BMI, which requires measurement of weight and height of the victim. But weighing patients with severe injuries is possible only in the presence of special scales, which are not in every hospital. Moreover, many patients come hemodynamically unstable. Their verticalization is impossible due to mixed trauma (skeletal, spinal cord and
TBI), when internal bleeding is suspected and in other situations. Therefore, it is important to find an alternative, and the most promising in this aspect is the WC.

WC is informative for determining cardiovascular risk factors in immobilized patients as a result of spinal cord injury. In such cases, the standard definition of BMI requires special weights and is, therefore, very complicated. The authors consider WC to be a simple and even more sensitive alternative to $\mathrm{BMI}$ in this patient population [16]. We have shown that the informative WC is not inferior to BMI in assessing the risk of injury of the lower extremities. Moreover, the combined use of $\mathrm{WC}$ and $\mathrm{BMI}$ is most informative [17]. WC measurement is used most often to determine the cardiometabolic risk [8]. We have no information on the use of WC in assessing the risk of a negative abdominal trauma.

\section{CONCLUSIONS}

1. Obesity increases the incidence of complications and mortality in victims of abdominal trauma, and is a marker of a negative prognosis.

2. Traditional assessment of BMI during hospitalization in most victims with abdominal trauma is not possible due to the severity of the condition and/or the presence of combined injuries.

3. A good alternative to determining obesity in victims with abdominal trauma is a WC (more than $88 \mathrm{~cm}$ in women and more than $102 \mathrm{~cm}$ in men).

The prospect of further research is to determine the impact of anthropometric indicators on the course of the post-traumatic period, taking into account the features of the primary trauma and the severity of functional disorders.

\section{REFERENCES}

1. Gönültaş F, Kutlutürk K, Gok AFK, Barut B, Sahin TT, Yilmaz S. Analysis of risk factors of mortality in abdominal trauma. Ulusal Travma ve Acil Cerrahi Dergisi. 2020;26(1):43-49.

2. Seliverstov PA, Shapkin YG. Ocenka tyazhesti i prognozirovanie iskhoda politravmy: sovremennoe sostoyanie problemy (obzor) [Assessment of severity and prognosis of polytrauma outcome: the current state of the problem (review)]. Sovremennye tehnologii v medicine. 2017;9(2): 207-218. (Ru).

3. Guzman-Martinez AM, Garcia-Rodriguez 0, Ramos-Melendez E0, Guerrios-Rivera L, Rodriguez-OrtizP. Morbidity and mortality of hispanic trauma patients with diabetes mellitus. European Journal of Trauma and Emergency Surgery. 2020;46(4):887-893.

4. Samoborec S, Simpson P, Hassani-Mahmooei B, Ruseckaite R, Giummarra $M$, Ayton D, Evans S. Impact of comorbidity on health outcome after a transport-related injury. Injury Prevention. 2020;26(3):254-261.

5. Global burden of 87 risk factors in 204 countries and territories, 1990-2019: a systematic analysis for the Global Burden of Disease Study 2019. Lancet 2020;396:1223-1249

6. Chen AK, Jeffcoach D, Stivers JC, McCullough KA, Dirks RC, Boehnke RJ, Sue L, Kwok AM, Wolfe MM, Davis JW. The impact of obesity on severity of solid organ injury in the adult population at a Level I trauma center. Trauma Surgery and Acute Care Open. 2019;4(1):e000318. doi: 10.1136/ tsac0-2019-000318. 
7. Fu CY, Bajani F, Butler C, Welsh S, Messer T, Kaminsky M, Starr F, Dennis A, Schlanser V, Mis J, Poulakidas S, Bokhari F. Morbid obesity's silver lining: an armor for hollow viscus in blunt abdominal trauma. World Journal of Surgery. 2019;43(4):1007-1013.

8. Ross R, Neeland IJ, Yamashita S, Shai I, Seidell J, Magni P, Santos RD, Arsenault B, Cuevas A, Hu FB, Griffin BA, Zambon A, Barter P, Fruchart $J C$, Eckel RH, Matsuzawa Y, Després JP. Waist circumference as a vital sign in clinical practice: a Consensus Statement from the IAS and ICCR Working Group on Visceral Obesity. Nature reviews. Endocrinology. 2020;16(3):177-189.

9. Afshin A, Forouzanfar MH, Reitsma MB, Sur P. Health effects of overweight and obesity in 195 countries over 25 years. New England Journal of Medicine. 2017;377:13-27.

10. Krakauer NY, Krakauer JC. Anthropometrics, metabolic syndrome, and mortality hazard. Journal of Obesity, 2018;2018:9241904. doi: 10.1155/2018/9241904

11. Pickkers P, de Keizer N, Dusseljee J, Weerheijm D, van der Hoeven JG, Peek N. Body mass index is associated with hospital mortality in critically ill patients: an observational cohort study. Critical Care Medicine. 2013;41(8):1878-83.

12. Ditillo M, Pandit V, Rhee P, Aziz H, Hadeed S, Bhattacharya B, Friese RS, Davis K, Joseph B. Morbid obesity predisposes trauma patients to worse outcomes: a National Trauma Data Bank analysis. Journal of Trauma and Acute Care Surgery. 2014;76(1):176-179.

13. Glance LG, Li Y, Osler TM, Mukamel DB, Dick AW. Impact of obesity on mortality and complications in trauma patients. Annals of surgery. 2014;259(3):576-581.

14. Durbin S, DeAngelis R, Peschman J, Milia D, Carver T, Dodgion C. Superficial surgical infections in operative abdominal trauma patients: a trauma quality improvement database analysis. Journal of Surgical Research. 2019;243:496-502.

15. Fu CY, Bajani F, Bokhari M, Tatebe LC, Starr F, Messer T, Kaminsky M, Dennis A, Schlanser V, Mis J, Toor R, Poulakidas S, Bokhari F. Obesity is associated with worse outcomes among abdominal trauma patients undergoing laparotomy: a propensity-matched nationwide cohort study. World Journal of Surgery. 2020;44(3):755-763.

16. Ravensbergen HR, Lear SA, Claydon VE. Waist circumference is the best index for obesity-related cardiovascular disease risk in individuals with spinal cord injury. Journal of Neurotrauma. 2014;31(3):292-300.
17. Nye NS, Carnahan DH, Jackson JC, Covey CJ, Zarzabal LA, Chao SY, Bockhorst AD, Crawford PF. Abdominal circumference is superior to body mass index in estimating musculoskeletal injury risk. Medicine and Science in Sports and Exercise. 2014;46(10):1951-1959.

\section{ORCID and contributionship:}

Madona O. Gogiya: 0000-0001-7891-6922 $2^{B, D}$

Igor V. Belozorov: 0000-0002-4102-3220 A,F

Vira V. Zlatkina: 0000-0002-7153-4064 ${ }^{E}$

Iuliia M. Mozgova: 0000-0002-1923-8831 ${ }^{E}$

Maksym E. Vodka: 0000-0002-3641-0867 ${ }^{E}$

Oleksandr E. Feskov: 0000-0003-2601-8252 C,F

Mykhailo S. Myroshnychenko: 0000-0002-6920-8374 ${ }^{B}$

\section{Conflict of interest:}

The Authors declare no conflict of interest.

\section{CORRESPONDING AUTHOR Mykhailo S. Myroshnychenko}

Pathological Anatomy Department, Kharkiv National Medical University str. Svetlaya 27A, apt. 70, 61129, Kharkiv, Ukraine tel: +380501699763

e-mail:msmyroshnychenko@ukr.net

Received: 27.04.2021

Accepted: 29.07.2021

A - Work concept and design, B - Data collection and analysis, C - Responsibility for statistical analysis, D-Writing the article, E-Critical review, $\mathbf{F}$ - Final approval of the article 